\title{
PENINGKATAN KESEJAHTERAAN HIDUP MASYARAKAT MELALUI PENGEMBANGAN ECO-HOMESTAY DI DESA AMPELGADING KECAMATAN TIRTOYUDO KABUPATEN MALANG
}

\author{
Andy Wibisono \\ Program Diploma Kepariwisataan Universitas Merdeka Malang \\ Jl. Bandung No. 1 Malang
}

Korespodensi dengan Penulis:

Andy Wibisono: Telp: 08384809 8236; Fax. 0341570371

E-mail: nathazendy@gmail.com

\begin{abstract}
Tourism industry has an important role in term of extending business and working opportunity by developing local potency, building urban and rural area and enlarging national income. It should be done to enhance public welfare. This study aims to: 1. Analyzing social condition, economy and social-culture which occur in Ampelgading village of Malang Regency; 2. Describing plantation, tourism, and eco-tourism potency in that village which can be developed; 3. Describing strength, weakness, threat and opportunity in term of plantation, tourism, and eco-tourism potencyin that village; 4. Describing a new working opportunity in tourism industry which can be used by local society in order to maximize income and minimize the number of poor people around that village. Data Collection techniques were used that observation, interview and documentation. This research uses a Participatory Rural Appraisal method (PRA), Focused Group Discussion (FGD), and SWOT analysis. The result of this study shows that Ampelgading village has a very extraordinary tourism interest in term of ecotourism and agricultural. In order to maximize the strength, it needs a good collaboration between tourism organization and local government. The developing of the village will impact to the development of people around it. Nowadays, there are several houses which have been used as lodging or homestay for tourist.
\end{abstract}

Keywords: Public Welfare, Eco-tourism, Homestay

Kepariwisataan mempunyai kesejahteraan dan kemakmuran peranan penting untuk memperluas rakyat serta memupuk rasa cinta dan memeratakan kesempatan tanah air, memperkaya kebudayaan berusaha dan lapangan kerja, nasional dan memantapkan mendorong pembangunan daerah, memperbesar pendapatan nasional pembinaannya dalam rangka dalam rangka meningkatkan memperkukuh jati diri bangsa dan 
mempererat persahabatan antar bangsa.

Kabupaten Malang merupakan daerah yang memiliki potensi pariwisata dan ekoagrowisata yang bervariatif dan sangat kaya sehingga dijuluki Bumi Agrowisata. Kabupaten Malang juga merupakan salah satu kota masuk dalam konsep KSPN (Kawasan Strategis Pariwisata Nasional) di dalam RIPPARNAS (Rencana Induk Kepariwisataan Nasional) Tahun 2010 - 2025.

Salah satu tujuan dalam program pembangunan kabupaten malang Tahun 2011 - 2015 yaitu mewujudkan pertumbuhan ekonomi yang berkualitas dan berkelanjutan terutama melalui pengembangan agroindustri, pariwisata dan ekonomi pedesaan.

Namun demikian dampak pertumbuhan dan pengembangan potensi wisata tersebut masih belum merata dan berpengaruh signifikan terhadap kesejahteraan masyarakat di beberapa wilayah di Kabupaten Malang. Jumlah penduduk miskin di Kabupaten Malang tahun 2014 mencapai jumlah 280.300 / 11.07 persen dari total jumlah penduduk 2.446.218 jiwa (BPS Kabupaten Malang, 2011).

Sedangkan kondisi tingkat kesejahteraan masyarakat di Kecamatan Tirtoyudo berdasarkan pendataan Rumah Tangga Miskin (RTM) yang diperoleh dari data Dinas Pemberdayaan Masyarakat dan Desa Kabupaten Malang (2009) adalah sejumlah 4.281 (sangat miskin 294, miskin sejumlah 1,527, hampir miskin sejumlah 2,460) dari 155.745 Rumah Tangga / KK yang ada di Kabupaten Malang. Jadi dapat dikatakan jumlah prosentase keluarga miskin di kecamatan Tirtoyudo masih kurang lebih 36,3\% dari total jumlah penduduk di desa tersebut.

Pengembangan kepariwisataan tidak hanya mampu meningkatkan pendapatan asli daerah semata, yang lebih penting kepariwisataan di desa tersebut harus mampu memberdayakan masyarakat sendiri sehingga warga desa merasa memiliki, melaksanakan, melestarikan, dan pada akhirnya dapat meningkatkan pendapatan melalui cara memberikan lapangan kerja dan kesempatan 
berusaha. Apabila dapat dikelola secara maksimal objek wisata ini dapat memberikan manfaat yang besar bagi pemerintah maupun masyarakat setempat.

Sebagaimana Desa Ampelgading memiliki karakteristik dan potensi sebagai objek daya tarik wisata berbasis Eko-Agrowisata dimana pengembangan ditekankan pada konsep mempertahankan kelestarian alam dan daya dukung lingkungan, yang dilengkapi dengan fasilitas memadai bagi wisatawan sesuai dengan Satu Visi "Merencanakan, Melaksanakan dan Memaknai Hasil Pembangunan RPJMD Kabupaten Malang 2011-2015 dan Visi dan Misi Visi Bupati Malang 2011-2015 yaitu MADEP MANTEB, terwujudnya masyarakat Kabupaten Malang yang Mandiri, Agamis, Demokratis, Produktif, Maju, Aman, Tertib dan Berdaya Saing. Delapan kunci yang diyakini dapat mewujudkan peningkatan kemakmuran dan kesejahteraan masyarakat Kabupaten Malang baik materiil maupun spiritual (SATATA GAMA KARTA RAHARJA).
Dengan potensi yang ada di desa Ampelgading Kecamatan Tirtoyudo maka kerja sama yang baik antara instansi pemerintah dan lembaga kemasyarakatan yang ada seharusnya dapat menciptakan berbagai alternatif lapangan pekerjaan. Selama ini, masyarakat memang kurang diberdayakan bagi pengembangan pariwisata sehingga masyarakat hanya menjadi penonton ketika potensi wisata di daerah mereka dikelola oleh pihak swasta atau pemerintah tanpa bisa menikmati hasil dari daerahnya sendiri. Potensi yang ada belum dapat berjalan secara maksimal sehingga dapat menciptakanberbagai lapangan pekerjaan baru menurut peneliti adalah mengembangkan potensi wisata.

Dalam rangka meningkatkan kesejahteraan dan tingkat perekonomian masyarakat, maka masyarakat perlu dilibatkan secara aktif dalam program pengembangan homestay berbasis ekologi yang ada di daerahnya, dalam hal ini masyarakat 
Desa Ampelgading dan jika program ini berhasil akan dikembangkan lagi di beberapa desa maupun kecamatan yang ada di sekitar Desa Ampelgading Kecamatan Tirtoyudo Kabupaten Malang.

Tujuan dalam penelitian ini adalah 1. Menganalisis kondisi sosial, ekonomi dan budaya masyarakat yang berada di Desa Ampelgading Kecamatan Tirtoyudo Kabupaten Malang. 2. Mendeskripsikan potensipotensi perkebunan, pariwisata dan ekowisata yang berada di sekitar Desa Ampelgading Kecamatan Tirtoyudo Kabupaten Malang yang mempunyai peluang untuk dikembangkan (to growth), 3. Mendeskripsikan Streghtness, Weakness dan Threat (perencanaan dan pemanfaatan) dalam pengembangan potensi perkebunan, pariwisata dan ekowisata di Desa Ampelgading Kecamatan Tirtoyudo Kabupaten Malang, 4. Mendeskripsikan kesempatan peluang kerja baru di bidang pariwisata yang bisa dimanfaatkan oleh Local Society guna meningkatkan pendapatan perkapita masyarakat setempat dan mengurangi jumlah warga miskin di
Desa Ampelgading Kecamatan Tirtoyudo Kabupaten Malang.

\section{METODE PENELITIAN}

Jenis penelitian yang digunakan adalah peneltiian deskriptif kualitatif yaitu adalah penggambaran secara menyeluruh tentang bentuk, fungsi, dan makna ungkapan larangan. Hal ini sejalan dengan pendapat Bogdan dan Taylor (1975) dalam Moleong (2002: 3) yang menyatakan "metodologi kualitatif" sebagai prosedur penelitian yang menghasilkan data deskriptif berupa kata-kata tertulis atau lisan dari orangorang dan perilaku yang dapat diamati.

Lokasi penelitian dilakukan di Desa Ampelgading Kecamatan Tirtoyudo Kabupaten Malang yaitu sebuah desa yang memiliki potensi ekowisata, agrowisata/perkebunan serta beberapa potensi di sektor pariwisata lainnya.

Variable dalam peneltian ini terdiri atas 2 variabel yaitu variable bebas / variable yang mempengaruhi (x) adalah pengembangan ecohomestay dan variable terikat / variable yang 
dipengaruhi (y) adalah kesejahteraan masyarakat.

Sumber data primer dalam penelitian ini kepala desa, operator pengelola wisata desa ampelgading, pengelola homestay, lembaga pariwisata (POKDARWIS) serta masyarakat desa ampelgading, sedangkan data sekunder diperoleh dari studi pustaka, artikel, jurnal penelitian, internet dan sumber data lain yang terkait dengan penelitian ini.

Teknik pengumpulan data pada penelitian ini melalui studi lapangan (filed research), wawancara secara terstruktur dan dokumentasi. Metode analisis data menggunakan pendekatan participatory research (diskusi kelompok dan wawancara kepada key persons) dengan alat analisis SWOT. Hal-hal yang menjadi perhatian adalah kondisi sosial, ekonomi, masyarakat lokal dan potensi wisata, ekowisata, perkebunan serta wisatawan yang berkunjung dan homestay tempat singgah wisatawan di desa tersebut.

\section{HASIL DAN PEMBAHASAN}

\section{A. Hasil Penelitian}

1. Profil Kecamatan Tirtoyudo dan

Desa Ampelgading

Kecamatan Tirtoyudo adalah salah satu dari 33 kecamatan di Kabupaten Malang yang mempunyai karaterikstik tersendiri yang jarang dimiliki oleh kecamatan lain. Kecamatan Tirtoyudo memanjang dari arah selatan ke utara dari ujung selatan daerah pantai terletak di sebelah tenggara Kota Malang dengan jarak kurang lebih $48 \mathrm{~km}$ dengan batas-batas wilayah sebagai berikut:

$$
\begin{aligned}
& \text { Sebelah Utara : } \\
& \text { Kecamatan Wajak } \\
& \text { Sebelah Timur : } \\
& \text { Kecamatan Ampelgading } \\
& \text { Sebelah Selatan : Samudra } \\
& \text { Indonesia } \\
& \text { Sebelah Barat : } \quad \text { Kec. } \\
& \text { Dampit dan Sumbermanjing } \\
& \text { Wetan }
\end{aligned}
$$

Kecamatan Tirtoyudo merupakan wilayah yang terletak di tenggara Ibukota Kabupaten Malang, awalnya Kecamatan Tirtoyudo adalah bagian dari Kecamatan Ampelgading.

Kondisi Monografi Desa Ampelgading Kecamatan Tirtoyudo Kabupaten Malang: Secara 
administratif luas wilayah desa Ampelgading 1064,29 dengan ketinggian wilayah 680 MDPL. Jumlah penduduk per akhir agustus 2013 sebanyak 4382 orang laki-laki, dan 4606 perempuan. Luas perkebunan dengan komoditas utama kopi seluas 96 Ha \& tebu 101 Ha. Jenis kopi yang banyak di tanam adalah robusta. Kesenian tradisional desa Ampelgading diantaranya terbang jidor, jaranan \& campur sari. Bahasa daerah yang digunakan adalah bahasa jawa \& madura.

Terdapat beberapa potensi baik di sektor pariwisata maupun perkebunan yang dimiliki oleh desa Ampelgading yang dapat dikembangkan menjadi produk unggulan sebagi berikut:

a. Perkebunan kopi Robusta terbaik khas Dampit

b. Perkebunan Salak Pondoh

c. Perkebunan cengkeh beserta penyulingan minyak cengkeh dan nilam

d. Perkebunan buah kesemek

e. Perkebunan Coklat f. Peninggalan purbakala jaman Majapahit berupa candi Jawar

g. Pemandangan Gunung Semeru serta akses tracking Gunung Semeru

\section{Analisis SWOT Desa} Ampelgading

Berikut deskripsi kekuatan, kelemahan, peluang \& ancaman Desa Ampelgading Kecamatan Tirtoyudo Kabupaten Malang berdasarkan hasil observasi, wawancara, diskusi serta pendapat dari keyperson pembina POKDARWIS sebagai berikut:

1. Kekuatan (Strengthness)

Proyeksi pengembangan Desa Ampelgading Kecamatan Tirtoyudo Kab. Malang memiliki masa depan yang cukup baik. Hal ini dipengaruhi oleh beberapa faktor yang merupakan kekuatan antara lain :

a. Kota Malang merupakan kota tujuan wisata di Jawa Timur, sedangkan distribusi wisata sebagian besar menuju wilayah Kabupaten Malang. Hal ini dipandang 
sebagai pasar yang sangat potensial.

b. Obyek wisata di Desa Ampelgading memiliki karakteristik yang tidak dimiliki oleh desa-desa lain di Jawa Timur seperti halnya koleksi tanaman perkebunan yang telah terkenal hasil produksinya di dataran Eropa dan buahbuahan langkah serta peninggalan sejarah jaman kerajaan Majapahit.

c. Adanya hutan lindung yang menambah suasana obyek yang sangat alami dilereng gunung Semeru dimana merupakan tempat pendakian utama bagi para wisatawan minat khusus.

d. Desa Ampelgading Kecamatan Tirtoyudo Kabupaten Malang masih belum banyak mengalami pencemaran dan mudah untuk di kelola.

e. Adanya potensi tenaga kerja di desa sekitar yang menjadi pendukung. f. Desa Ampelgading memiliki budaya lokal yang dapat menunjang atraksi wisata.

g. Lokasi desa Ampelgading cukup dekat dengan situs purbakala Candi Jawar yang merupakan obyek wisata potensial, sehingga desa Ampelgading diharapkan dapat menjadi daerah wisata potensial.

2. Kelemahan (Weakness)

Disamping kekuatan yang dimiliki, Desa Ampelgading Kecamatan Tirtoyudo Kabupaten Malang teridentifikasi memiliki faktor yang menjadi kekurangan atau kelemahan, antara lain:

a. Sarana penunjuk jalan (Sign Board) yang kurang baik.

b. Jarak tempuh yang cukup jauh sekitar 1,5 jam perjalanan darat dari Kota Malang.

c. Dukungan masyarakat dan aparat desa yang masih kurang. 
d. Kelembagaan desa yang menangani kegiatan wisata masih belum terbentuk, sedangkan untuk sementara penanganan kegiatan wisata ditangani oleh team kecil pencetus gagasan desa wisata Ampelgading.

e. Belum tersedianya tenaga terampil dalam bidang pariwisata seperti tenaga pemandu wisata dan sebagainya.

\section{Peluang (Opportunity)}

Berikut beberapa peluang yang dimiliki oleh desa Ampelgading Kecamatan Tirtoyudo Kabupaten Malang:

a. Dengan terbentuknya status Kabupaten Malang yang menjadi tujuan wisata merupakan modal yang sangat besar. Hal ini akan mendorong para operator untuk mempromosikan serta mencantumkan kabupaten Malang ke dalam program kunjungan atau paket wisata sebagai produk yang di jual oleh Biro Perjalanan Wisata khususnya serta masyarakat lokal.

b. Desa wisata yang berbasis tanaman perkebunan dan industri dimana jenis tanaman ini merupakan objek yang sangat menarik bagi wisatawan Eropa. Berdasarkan pengamatan para stakeholder di bidang pariwisata, objek agrowisata yang menarik bagi wisatawan mancanegara adalah koleksi tanaman perkebunan dan industri sehingga dapat disebut sebagai objek agrowisata yang sebenarnya karena ditampilkan secara natural.

c. Lokasi desa yang terletak di jalur provinsi Malang Selatan dapat menjadi pilihan untuk transit bagi wisatawan mancanegara yang menuju kota Lumajang-Jember-Banyuwangi.

4. Ancaman (Threat)

Sebagai ancaman yang diperkirakan akan timbul yaitu adanya persaingan yang cukup 
agresif dari kota dan Kabupaten sekitar yang menjadi pesaing bagi pengembangan desa wisata.

\section{B. Pembahasan}

Dilihat dari segi potensi daya tarik wisata bahwa desa ampelgading memiliki komposisi daya tarik wisata yang menarik dan bervariatif diantaranya obyek wisata perkebunan, situs sejarah, akses menuju daya tarik wisata gunung semeru dan budaya masyarakat yang arif sehingga dapat dijadikan modal penting menarik kunjungan wisatawan lokal maupun asing guna pengembangan sektor pariwisata.

Letak desa ampelgading yang strategis yang mana merupakan jalur alternatif menuju daerah / kota yang juga memiliki potensi wisata yang popular seperti lumajang, jember dan banyuwangi sehingga dapat dimanfaatkan sebagai pilihan tempat transit bahkan dapat dijadikan salah satu program kunjungan wisata bagi wisatawan yang akan berkunjung ke lumajang, jember dan banyuwangi.

Pengelolaan dan pengembangan pariwisata di desa ampelgading juga harus didukung penuh oleh lembaga desa dan melibatkan langsung masyarakat desa serta didukung dengan pembentukan lembaga / organisasi pariwisata seperti lembaga desa wisata atau POKDARWIS sebagaimana dapat membantu percepatan pengembangan pariwisata di desa tersebut. Sekaligus dilakukan pendampingan kegiatan Pokdarwis secara kelompok sesuai dengan pendapat Supriadi (2016) bahwa pendampingan sebuah kelompok dapat dijalankan dengan melakukan Orientasi dan kegiatan pelatihan sensitivitas kelompok, mengadakan pertemuan yang efektif, melakukan teknik mengambil keputusan, melakukan perbaikan pengajaran, melakukan kunjungan yang didampingi dan pengembangan instrument evaluasi pendampingan.

\section{KESIMPULAN}

Berdasarkan hasil peneltiian dan pembahasan masalah di atas maka dapat di simpulkan bahwa:

1. Budaya masyarakat setempat, kondisi alam yang masih alami, kekayaan hasil bumi yang 
melimpah dengan sebagian besar mata pencaharian masyarakat setempat adalah berkebun merupakan kearifan lokal yang dapat dijadikan peluang dalam peningkatan kesejahteraan hidup masyarakat setempat di bidang pariwisata tanpa mengubah aktifitas masyarakat setempat yang semula.

2. Pengembangan sektor pariwisata dengan menjadikan desa ampelgading sebagai desa wisata berbasis ecoagrotourism / eko-agrowisata yang memiliki potensi perkebunan, pariwisata \& ekowisata.

3. Pengembangan sarana tempat tinggal bagi wisatawan seperti homestay berbasis ekologi merupakan salah satu peluang yang dapat di terapkan di desa ampelgading guna menunjang kegiatan wisata guna menarik jumlah dan minat kunjungan wisatawan semaksimal mungkin sehingga berdampak pada peningkatan kesejahteraan masyarakat setempat.
4. Pelibatan / peran aktif masyarakat lokal sebagai tour operator, tenaga pemandu wisata, penyedia jasa catering, dan sebagainya dapat dijadikan alternatif peluang kerja baru bagi msyarakat lokal.

Saran yang diberikan berdasarkan kesimpulan di atas adalah lembaga desa mengadakan musyawarah desa guna membentuk organisasi / lembaga yang khusus menangani pengembangan pariwisata di desa tersebut serta mendukung penuh program-program yang dibuat dan melaksanakan pendampingan terhadap kegiatan-kegiatan yang diselenggarakan.

\section{UCAPAN TERIMAKASIH}

Artikel Ilmiah ini merupakan hasil dari kegiatan Penelitian kemudian di sarikan menjadi Artikel Ilmiah ini dan dalam tulisan ini Kami sempatkan untuk menyampaikan banyak terimakasih atas terwujudnya tulisan ini kepada Dirjen Pendidikan Tinggi. Kopertis Wilayah VII yang telah memberikan dukungan dana untuk kegiatan penelitian kali ini. 


\section{DAFTAR PUSTAKA}

Badan Pusat Statistik, 2011. Jumlah dan Persentase Penduduk Miskin, Garis Kemiskinan, Indeks Kedalaman Kemiskinan (P1), dan Indeks Keparahan Kemiskinan (P2) Kabupaten Malang, 2012 - 2014. Kabupaten Malang: Badan Pusat Statistik.

Kurniawan, Widi. 2005. Sentra Pengembangan Desa Wisata di Desa Tirtoadi ,Kecamatan Mlati, Kabupaten Sleman. Tugas Akhir Program Diploma III Kepariwisataan Fakultas Ilmu Budaya Universitas Gadjah Mada. Yogyakarta.

Pendit, I Nyoman S.1999. Ilmu Pariwisata Sebuah Pengantar
Perdana. PT. Pradnya Paramita. Jakarta

Peraturan Pemerintah RI No. 50 Tahun 2011 tentang Rencana Induk Pembangunan Kepariwisataan Nasional (Ripparnas) Tahun 2010-2025

Supriadi, B. 2016. Kompetensi Pendampingan Pemandu Wisata Lokal Sebagai Developers Of People. Jurnal Pariwisata Pesona, 1(2). Retrieved from http://jurnal.unmer.ac.id/i ndex.php/jpp/article/view/517 Undang-Undang Republik Indonesia No 10 Tahun 2009. Tentang Kepariwisataan 